\section{LCHF: Look at the full picture}

To the Editor: The article 'Low-carbohydrate and high-fat intake can manage obesity and associated conditions: Occasional survey ${ }^{\text {'[1] }}$ by T D Noakes refers.

When discussing the health benefits of their diet, low-carbohydrate, high-fat (LCHF) advocates, from Atkins to the acolytes after him, give all the credit to LCHF eating. In their conclusions, they could very well be confusing cause and correlation. When obese people lose weight, their cardiovascular risk parameters improve irrespective of the mode of weight loss, whether it was LCHF, high-carbohydrate, lowfat (HCLF), calorie restriction, or even cocaine abuse or contracting tuberculosis. The weight loss itself is the main contributor to improved health, through a decreased pro-inflammatory state, and although this is a well-established fact in the medical literature, it never gets mentioned in the conclusions of a LCHF article.

As medical professionals, we would welcome a magic cure for obesity, even if it is LCHF. This diet certainly performs well over the short term (months), but there are no data on its long-term safety (decades). This short-term/long-term dichotomy never finds its way into the conclusions of the LCHF article

Long-term efficacy is questionable. The attrition rate is very high, much higher than with other diets. LCHF is easy and simple enough, until a plate of cookies is put in front of you. And it is expensive, well outside the budget of the lower socio-economic classes, which is the population group where obesity prevalence is the highest. To be fair to his readers and science, Noakes should have mentioned this in his discussion.

Where LCHF is right is in agreeing that we eat and drink too many processed and refined carbohydrates, e.g. white flour, breakfast cereals, sweets, desserts, cool drinks. Our current sugar consumption is four times higher than a century ago.

To illustrate that LCHF's success is about more than LCHF eating, I refer to the second case study (obese man lost $75 \mathrm{~kg}$ ). He was one of the patients in our bariatric (weight loss) surgery programme, but scared of the operation. At the end of one of my motivational talks to the bariatric surgery support group, he asked me if what I had presented could be an alternative to the surgery. He then voluntarily withdrew from the bariatric work-up (contrary to what Noakes writes, the anaesthesia had never been deemed too dangerous for him - I know, because I am anaesthetist on this programme) and had a close look at his lifestyle. He decided to change his life: he started attending a support group, took up some physical activity and went on LCHF. LCHF was a stepping-stone, not a miracle cure but one of many interventions that collectively contribute to successful weight control. He continues to attend the support group, makes a point of eliminating all refined carbs, sugar and alcohol from his diet, and limits his portion sizes and fat intake. Endocrinologists and dieticians have for decades been prescribing LCHF for selected patients but if bad habits are not changed, the weight returns. If Noakes had included the full story of Case 2, instead of making LCHF look like a miracle cure, his readers would have benefited from a more realistic look at the diet he believes in. He still wouldn't have scored high marks for design and methodology, but he would have made more of us reflect on the merit in his message. And that is, after all, reason to read medical journals.

It remains puzzling how this article found its way past peer review into the SAMJ. Studies that run over decades do seem to indicate that a high fat content in the diet increases the risk for cardiovascular disease, and that a high consumption of red meat, through some yet unknown mechanism, might increase the risk for diabetes (a disease that Noakes aims to 'cure' with his approach).

\section{Luc Evenepoel}

N1 City Hospital, Cape Town, South Africa

luc.evenepoel@gmail.com 1. Noakes, TD. Low-carbohydrate and high-fat intake can manage obesity and associated conditions:
Occasional survey. S Afr Med J 2013;103(11):826-830. [http://dx.doi.org/10.7196/SAMJ.7302]

Editors' note: Prof Noakes' article was published in our Forum section because it did not meet the criteria required for original research. However, as a case series (a recognised approach to looking at particular clinical problems in medicine) it met the criteria to be included in Forum, specifically to generate discussion around a topic that is generating a lot of debate globally at present (see http://www.bbc.co.uk/news/health-24625808 and http://www. theguardian.com/lifeandstyle/2013/oct/22/butter-cheese-saturatedfat-heart-specialist in response to an editorial in the British Medical Journal (BMJ) recently).

Note that Forum articles do not go through the formal review process - the $S A M J$ is not so well endowed with colleagues willing to offer their time to review every submission. However, all submissions - including these letters to the Editor - are reviewed by an in-house review committee, as is the practice at all other general medical journals (the Lancet, the BMJ, etc.)

As to critics' claims that his paper was published only because of Noakes' 'fame' - this is untrue.

S Afr Med J 2014;104(1):5. DOI:10.7196/SAMJ/7793 